\title{
Collaborative Digital Literacy Practices among Adult Learners: Levels of Confidence and Perceptions of Importance
}

\author{
Laurie A. Sharp \\ Asst. Prof., John G. O’Brien Distinguished Chair in Education, West Texas A\&M \\ University, USA, lsharp@wtamu.edu
}

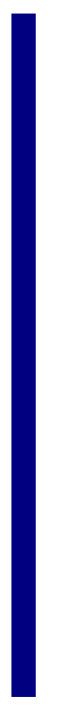

Technology has transformed learning at the postsecondary level and significantly increased the prevalence of digital learning environments. As adult educators approach instructional design, they must consider how to apply research-based practices that preserve the quality of instruction and provide adult learners with technology-based instruction that is relevant. One approach, the use of collaborative digital literacy practices, has been highlighted as a highly effective method. The current study explored perceived levels of confidence and importance with collaborative digital literacy practices among adult learners $(n=51)$ in digital learning environments by applying a quantitative pre-post test design. Data were analysed descriptively (i.e., frequency counts for experiences with five collaborative digital literacy practices) and inferentially (i.e., mean comparisons for perceived levels of confidence and importance were made with paired sample $t$ test statistical analyses). Findings revealed five statistically significant findings related to participants' perceived levels of confidence with collaborative digital literacy practices, and four statistically significant findings were reported for participants' perceived levels of importance. Implications associated with these finding were discussed, along with limitations and recommendations for future studies in this area.

Keywords: digital learning, adults, literacy, collaboration, confidence, importanc

\section{INTRODUCTION}

Technological advancements and digital tools have broadened the format of postsecondary instruction, and digital learning environments have grown significantly in popularity among adult learners (Hoskins, 2011). Although digital learning environments have increased the accessibility of educational opportunities, they also require different instructional design methods than traditional face-to-face learning environments (Linder-VanBerschot \& Summers, 2015; Scanlon, McAndew, \& O'Shea, 2015). The lack of physical presence in digital learning environments has challenged

Citation: Sharp, L. A. (2018). Collaborative Digital Literacy Practices among Adult Learners: Levels of Confidence and Perceptions of Importance. International Journal of Instruction, 11(1), 153-166. https://doi.org/10.12973/iji.2018.11111a 
adult educators to cultivate web-based learning environments that provide rigorous academic experiences and promote student success.

Recent literature has described several examples of effective instructional design methods used among adult learners in digital learning environments, such as

- adapting cognitive apprenticeship methods (CAM) with technology tools to provide opportunities for modeling, scaffolding, coaching, articulation, and reflection (Boling et al., 2014);

- creating virtual orientations and tutorials that familiarize learners with course expectations, content, and tools (Taylor, Dunn, \& Winn, 2015);

- embedding experts as resources for learners, such as a virtual librarian (Mudd, Summey, \& Upson, 2015);

- employing techniques that foster the development of self-regulation (Sharp \& Sharp, 2015); and

- facilitating collaboration and interaction through social networking (Eid \& AlJabri, 2016), group tasks (Ku, Tseng, \& Akarasriworn, 2013), and digital discourse (Kent, Laslo, \& Rafaeli, 2016).

These instructional design methods have reported positive results regarding course-level performance. Furthermore, each has also applied strategies linked to improved learner retention in digital learning environments, such as enabling access to virtual support services, applying a learner-centered approach, providing opportunities for interaction within web-based learning communities, and engaging students within the digital learning environment (Angelino, Williams, Natvig, 2007). As the popularity of digital learning environments continues to grow, Fabry (2009) emphasized the importance of continued research in this area to ensure that adult learners have continued access to quality educational experiences.

Existing literature has pointed to myriad benefits associated with the inclusion of collaborative learning tasks among adult learners (e.g., Laal \& Ghodsi, 2011; Tibbetts \& Hector-Mason, 2015). As digital learning environments become more prevalent, adult educators have begun to merge digital literacy practices with collaborative learning tasks through the use of technology tools, such as asynchronous discussions (McDougall, 2015), blogs (Chang \& Chang, 2014), microblog messages (Hsu \& Ching, 2012), wikis (Zheng, Niiya, \& Warschauer, 2015), and technology tools to facilitate paired peer feedback exercises (Ching \& Hsu, 2013). This shift has ushered in the concept of collaborative digital literacy practices, which has received a great deal of attention regarding its implementation with children and adolescent learners (Greenhow \& Gleason, 2012; Journell, 2008; Kissel, Hathaway, \& Wood, 2010; Ranker, 2015; Zheng, Lawrence, Warschauer, \& Lin, 2015). However, Jacobs, Castek, Pizzolato, Reder, \& Pendell (2014) noted that available literature for collaborative digital literacy practices specific to adult learners was extremely limited and required closer examination. 


\section{LITERATURE REVIEW}

In order to facilitate learning among adults, adult educators have been encouraged to utilize a learner-focused, andragogical model of teaching (Knowles, 1984; Knowles, Holton III, \& Swanson, 2015). An andragogical model of teaching acknowledges the self-directedness, motivation, and rich knowledge base that adults bring to their learning environments. An andragogical model of teaching also incorporates relevant learning experiences and problem-solving performance tasks throughout the instructional design. Although the concept of andragogy has been criticized for its lack of attention to sociocultural contexts associated with learning, it recognizes the unique characteristics among adult learners and establishes "adult education as a unique field of practice" (Merriam, 2001, p. 11).

Applying andragogical principles into the instructional design of digital learning environments has been noted as an essential way to create engaging and motivating learning experiences tailored specifically for adult learners (Conaway \& Zorn-Arnold, 2015, 2016a, 2016b). According to Knowles, Holton III, and Swanson (2015), optimal learning among adult learners requires attention to the following adult learning principles:

- Adults are intrinsically motivated to learn.

- Adults are inclined to learn when there is an obvious connection to their lives personally or professionally.

- Adults have current and past experiences as rich resources for learning.

- Adults prefer real-world learning contexts that incorporate a subject-centered, problem-solving approach.

- Adults learn best when they are empowered as autonomous, self-regulated learners.

- Adult require advanced information about a topic under study in order to determine its relevance.

Recently, Blackley and Sheffield (2015) coined the term "digital andragogy," which explored the use of "andragogical practices within a digitally expanded educational context" (p. 407). Blakely and Sheffield recognized that the current and prominent discourse related to $21^{\text {st }}$ century knowledge and skills provided a compelling reason to reevaluate andragogy and related adult learning principles within a digital context. Although Blakely and Sheffield limited their analyses to adult learners enrolled in a teacher education program, their findings have pointed to the need for further exploration with concepts related to the novel concept of digital andragogy.

\section{THEORETICAL FRAMEWORK}

The current study drew upon constructivist social learning theories and posited that learning is a social process during which knowledge is co-constructed (Vygotsky, 1978). Each learner brings their own experiences to collaborative learning experiences (Dewey, 1938), which when shared through peer interactions, have the potential to foster "critical thinking through discussion, clarification of ideas, and evaluation of others' ideas" (Gokhale, 1995, para. 36). With this in mind, the current study sought to expand the notion of digital andragogy by exploring the use of collaborative digital literacy 
practices among adult learners in digital learning environments. The following research questions guided this exploration:

- What level of confidence do adult learners have regarding the use of collaborative digital literacy practices in digital learning environments?

- What level of importance do adult learners place on the use of collaborative digital literacy practices in digital learning environments?

\section{METHOD}

\section{Participants}

Participants in the current study were adult learners enrolled in a graduate-level online course entitled Educational Research that was deployed during the Summer 2016 ( $n=$ 22) and Fall $2016(n=29)$ semesters. Participants included both males $(n=19)$ and females $(n=32)$ who were seeking a master's degree offered through the education department $(N=635)$ at a Level 5 university accredited by the Southern Association of Colleges and Schools Commission on Colleges (SACSCC) located in the Southern United States.

\section{Research Design}

The current study utilized a quantitative pre-post test design (Creswell, 2013). At the beginning of the semester, participants were randomly assigned to three different small groups. Small groups were utilized as a way for participants to develop understandings related to the course, while also developing familiarity with their small group members. Within each small group, participants engaged in structured learning experiences that required use of five different collaborative digital literacy practices scheduled to deploy at designated times during the semester. These included: (a) creation of a blog, (b) participation in an asynchronous discussion, (c) construction of a wiki, (d) exchange of microblog messages, and (e) the provision of paired peer feedback.

\section{Procedure}

Permission to survey all participants was granted by the University's Institutional Review Board (IRB). At the beginning of each semester, an email containing information about the study was sent to all students enrolled in the course. Participation was voluntary, and those who elected to participate in the study provided consent electronically. Pre-test instruments were administered before participants interacted with a designated collaborative digital literacy practice (i.e., blog, asynchronous discussion, wiki, microblog messages, and paired peer feedback), and post-test instruments were administered afterwards. Participants were allowed to direct questions about the study before, during, and after administration of pre-post test instruments to the researcher, who was also the professor of the course during both semesters.

\section{Variables and Measures}

Pre-test instruments were administered within separate online Google Forms and sought to obtain familiarity, level of confidence, and perceived importance with each respective 
collaborative digital literacy practice. Pre-test instruments included two closed-ended questions that asked participants to indicate whether the collaborative digital literacy practice had been used previously in an academic setting, as well as in a non-academic setting. Pre-test instruments also included two Likert-type items that used a 5-point scale for participants to rate their perceived levels of confidence with using each respective collaborative digital literacy practice, as well as their perceived levels of its importance for learning in a digital environment. After engagement with each collaborative digital literacy practice, participants completed corresponding post-test instruments, which were also administered as online Google Forms. The post-test instruments included two similar Likert-type items with which participants again rated their perceived levels of confidence and importance for each respective collaborative digital literacy practice.

\section{Data Analysis}

Quantitative data were collected from completed pre-post test instruments. Frequency counts were performed with closed-ended responses regarding participants' previous experiences with each collaborative digital literacy practice. Mean comparisons were conducted with Likert-type responses to test the following null hypotheses:

$\mathrm{H}_{0} 1$ : There is no statistically significant difference with participants' perceived levels of confidence with [blogs, asynchronous discussions, wikis, microblog messages, or paired peer feedback] before and after participation in the structured learning experiences.

$\mathrm{H}_{0}$ 2: There is no statistically significant difference with participants' perceived levels of importance with [blogs, asynchronous discussions, wikis, microblog messages, or paired peer feedback] before and after participation in structured learning experiences.

In order to make inferences to more general conditions, paired sample $t$-test statistical analyses were conducted with IBM SPSS Statistics software. Prior to conducting statistical analyses, each data set was inspected to confirm that each assumption was satisfied (Laerd Statistics, 2013). After this confirmation, the researcher established statistical significance at $a<.05, \beta=.20$, and effect sizes were reported as small (.20), medium (.50), or large (.80) for findings that showed statistical significance (Cohen, 1992).

Frequencies for participants' previous use with each collaborative digital literacy practice in academic and non-academic settings were reported in Table 1. These descriptive data demonstrated participants' existing knowledge and skills with each collaborative digital literacy practice. As shown in Table 1, participants had the most familiarity with asynchronous discussions in academic settings and paired peer feedback in both academic and non-academic settings. These data also showed that participants were generally unfamiliar with blogs, wikis, and microblog messages, particularly in academic settings. 
Table 1

Frequencies for previous use with collaborative digital literacy practices

\begin{tabular}{lccccc}
\hline & $n$ & Yes & $\%$ & No & $\%$ \\
\hline Blogs & 46 & & & & \\
$\quad$ Previous Academic Use & & 13 & 28.3 & 33 & 71.7 \\
$\quad$ Previous Non-Academic Use & & 14 & 30.4 & 32 & 69.6 \\
\hline Asynchronous Discussions & 47 & & & & \\
$\quad$ Previous Academic Use & & 26 & 55.3 & 21 & 44.7 \\
$\quad$ Previous Non-Academic Use & & 19 & 40.4 & 28 & 59.6 \\
\hline Wikis & 44 & & & & \\
$\quad$ Previous Academic Use & & -- & -- & 44 & 100 \\
$\quad$ Previous Non-Academic Use & 45 & & 2.3 & 43 & 97 \\
\hline Microblog Messages & & 2 & 4.4 & 43 & 95.6 \\
$\quad$ Previous Academic Use & & 14 & 31.1 & 31 & 68.9 \\
$\quad$ Previous Non-Academic Use & 45 & & & & \\
\hline Paired Peer Feedback & & 24 & 53.3 & 21 & 46.7 \\
$\quad$ Previous Academic Use & & 26 & 57.8 & 19 & 42.2 \\
$\quad$ Previous Non-Academic Use & & & &
\end{tabular}

Results from statistical testing for each of the mean comparisons for perceived levels of confidence and importance were reported in Table 2. Relevant descriptive statistics (i.e., sample sizes, means, and standard deviations) were included, as well as confidence intervals and effect sizes for statistically significant findings.

Table 2

Quantitative results from statistical testing

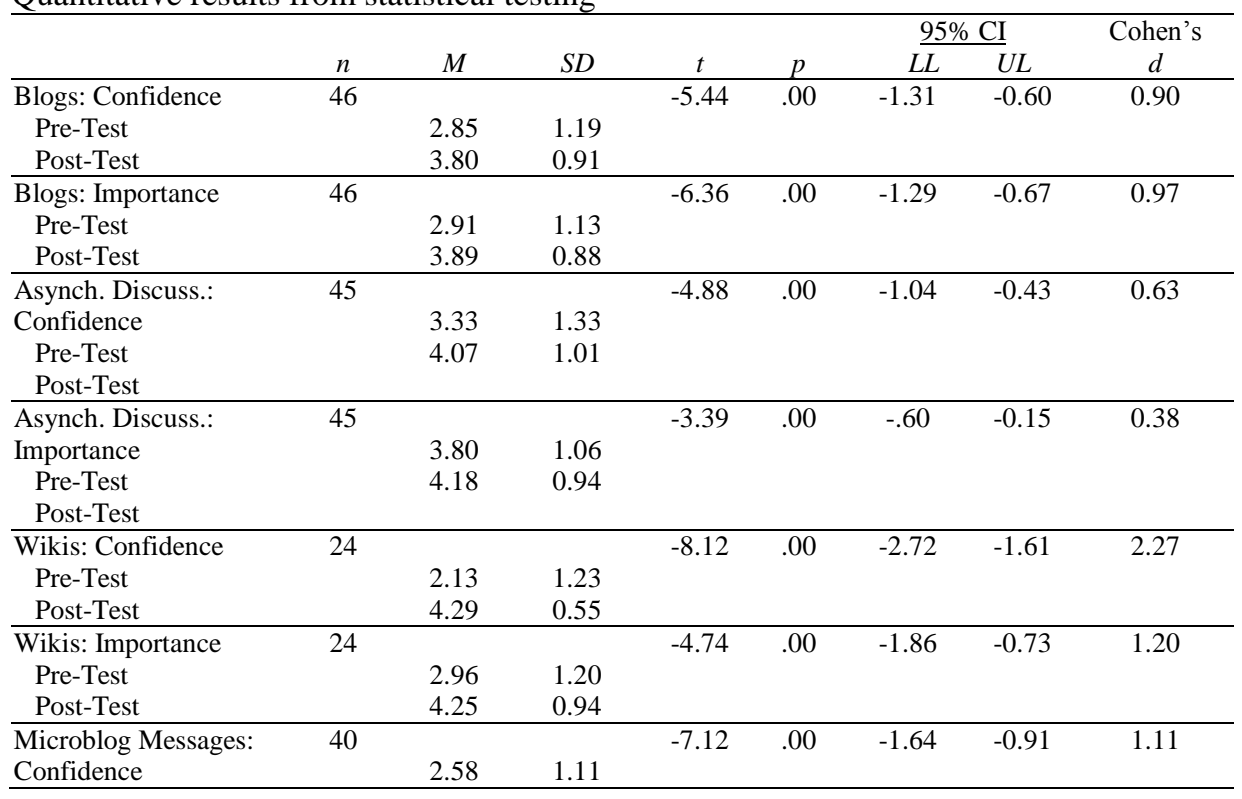




\begin{tabular}{|c|c|c|c|c|c|c|c|c|}
\hline $\begin{array}{l}\text { Pre-Test } \\
\text { Post-Test }\end{array}$ & & 3.85 & 1.17 & & & & & \\
\hline Microblog Messages: & 40 & & & -2.88 & .01 & -0.89 & -0.16 & 0.44 \\
\hline $\begin{array}{l}\text { Importance } \\
\text { Pre-Test } \\
\text { Post-Test }\end{array}$ & & $\begin{array}{l}3.10 \\
3.63\end{array}$ & $\begin{array}{l}1.26 \\
1.15\end{array}$ & & & & & \\
\hline $\begin{array}{l}\text { Paired Peer Feedback: } \\
\text { Confidence } \\
\text { Pre-Test } \\
\text { Post-Test } \\
\end{array}$ & 42 & $\begin{array}{l}3.52 \\
3.90\end{array}$ & $\begin{array}{l}1.09 \\
1.01\end{array}$ & -2.44 & .02 & -0.70 & -0.07 & 0.36 \\
\hline $\begin{array}{l}\text { Paired Peer Feedback: } \\
\text { Importance } \\
\text { Pre-Test } \\
\text { Post-Test }\end{array}$ & 42 & $\begin{array}{l}4.17 \\
4.43\end{array}$ & $\begin{array}{l}0.91 \\
0.86\end{array}$ & -1.86 & .07 & -0.55 & 0.02 & - \\
\hline
\end{tabular}

As shown in Table 2, nine statistically significant findings were reported among the ten mean comparisons. With respect to participants' perceived levels of confidence, statistical significance was found with all five collaborative digital literacy practices. With respect to participants' perceived levels of importance, statistical significance was found with blogs, asynchronous discussions, wikis, and microblog messages. These findings are further described in the following section.

\section{FINDINGS}

\section{Blogs}

As shown in Table 1, the majority of participants had no previous experience with use of blogs in both academic settings $(n=33,71.7 \%)$ and non-academic settings $(n=32$, $69.6 \%$ ). To test the two null hypotheses, paired samples $t$-tests were performed (see Table 2). With respect to the first null hypothesis, findings revealed that participants rated their levels of confidence with blogs higher after participation in the structured learning experience $(M=3.80, S D=0.91)$ than they did before $(M=2.85, S D=1.19)$. Further analyses of the data revealed that a statistically significant difference was present, which rejected the first null hypothesis; $t(45)=-5.44, p=.00$. Cohen's $d$ was calculated at 0.90, which was considered a large effect (Cohen, 1992).

With respect to the second null hypothesis, findings showed that participants rated their perceived levels of importance with blogs higher after participation in the structured learning experience $(M=3.89, S D=0.88)$ than they did before $(M=2.91, S D=1.13)$. Further analyses of the data revealed that a statistically significant difference was present, which rejected the second null hypothesis; $t(45)=-6.36, \mathrm{p}=.00$. Cohen's $d$ was calculated at 0.97, which was considered a large effect (Cohen, 1992).

\section{Asynchronous Discussions}

As shown in Table 1, slightly more than half of participants had previous experience with use of asynchronous discussions in academic settings $(n=26,55.3 \%)$, and approximately $40 \%$ of participants had experience with asynchronous discussions in non-academic settings $(n=19,40.4 \%)$. To test the two null hypotheses, paired samples $t$-tests were performed (see Table 2). With respect to the first null hypothesis, findings revealed that participants rated their levels of confidence with asynchronous discussions higher after participation in the structured learning experience $(M=4.07, S D=1.01)$ 
than they did before $(M=3.33, S D=1.33)$. Further analyses of the data revealed that a statistically significant difference was present, which rejected the first null hypothesis; $t(44)=-4.88, p=.00$. Cohen's $d$ was calculated at 0.63 , which was considered a medium effect (Cohen, 1992).

With respect to the second null hypothesis, findings showed that participants rated their perceived levels of importance with asynchronous discussions higher after participation in the structured learning experience $(M=4.18, S D=0.94)$ than they did before $(M=$ $3.80, S D=1.06)$. Further analyses of the data revealed that a statistically significant difference was present, which rejected the second null hypothesis; $t(44)=-3.39, p=.00$. Cohen's $d$ was calculated at 0.38 , which was considered a small effect (Cohen, 1992).

\section{Wikis}

As shown in Table 1, none of the participants had previous experience with use of wikis in academic settings $(n=44,100 \%)$, and all but one participant had no previous experience with wikis in non-academic settings $(n=43,97 \%)$. To test the two null hypotheses, paired samples $t$-tests were performed (see Table 2 ). These analyses only included data from participants from the Fall 2016 semester due to an internal issue with the wiki tool in the University's learning management system. This occurrence was beyond the control of the researcher; therefore, participants enrolled in the Summer 2016 semester were unable to complete the post-test, which reduced the sample size for the paired $t$-tests analyses. With respect to the first null hypothesis, findings revealed that participants rated their levels of confidence with wikis higher after participation in the structured learning experience $(M=4.29, S D=0.55)$ than they did before $(M=$ $2.13, S D=1.23)$. Further analyses of the data revealed that a statistically significant difference was present, which rejected the first null hypothesis; $t(23)=-8.12, p=.00$. Cohen's $d$ was calculated at 2.27, which was considered a large effect (Cohen, 1992).

With respect to the second null hypothesis, findings showed that participants rated their perception of importance with wikis higher after participation in the structured learning experience $(M=4.25, S D=0.94)$ than they did before $(M=2.96, S D=1.20)$. Further analyses of the data revealed that a statistically significant difference was present, which rejected the second null hypothesis; $t(23)=-4.74, p=.00$. Cohen's $d$ was calculated at 1.20, which was considered a large effect (Cohen, 1992).

\section{Microblog Messages}

As shown in Table 1, almost all participants had no previous experience with use of microblog messages in academic settings $(n=43,95.6 \%)$, and almost $70 \%$ of participants had no previous experience with microblog messages in non-academic settings $(n=31,68.9 \%)$. To test the two null hypotheses, paired samples $t$-tests were performed (see Table 2). With respect to the first null hypothesis, findings revealed that participants rated their levels of confidence with microblog messages higher after participation in the structured learning experience $(M=3.85, S D=1.17)$ than they did before $(M=2.58, S D=1.11)$. Further analysis of the data revealed that a statistically significant difference was present, which rejected the first null hypothesis; $t(39)=-7.12$, $p=.00$. Cohen's $d$ was calculated at 1.11 , which was considered a large effect (Cohen, 1992). 
With respect to the second null hypothesis, findings showed that participants rated their perceived levels of importance with microblog messages higher after participation in the structured learning experience $(M=3.63, S D=1.15)$ than they did before $(M=3.10$, $S D=1.26)$. Further analyses of the data revealed that a statistically significant difference was present, which rejected the second null hypothesis; $t(39)=-2.88, p=.00$. Cohen's $d$ was calculated at 0.44 , which was considered a small effect (Cohen, 1992).

\section{Paired Peer Feedback}

As shown in Table 1, almost half of the participants had previous experience with use of paired peer feedback in both academic settings $(n=24,53.3 \%)$ and non-academic settings $(n=26,57.8 \%)$. To test the two null hypotheses, paired samples $t$-tests were performed (see Table 2). With respect to the first null hypothesis, findings revealed that participants rated their levels of confidence with paired peer feedback higher after participation in the structured learning experience $(M=3.90, S D=1.01)$ than they did before $(M=3.52, S D=1.09)$. Further analyses of the data revealed that a statistically significant difference was present, which rejected the first null hypothesis; $t(41)=-2.44$, $p=0.02$. Cohen's $d$ was calculated at 0.36 , which was considered a small effect (Cohen, 1992).

With respect to the second null hypothesis, findings showed that participants rated their perceived levels of importance with paired peer feedback higher after participation in the structured learning experience $(M=4.43, S D=0.86)$ than they did before $(M=$ $4.17, S D=0.91)$. Further analyses of the data revealed that there was not a statistically significant difference, which failed to reject the second null hypothesis; $t(41)=-1.86, p$ $=0.07$.

\section{DISCUSSION}

The purpose of the current study was to explore the perceived levels of confidence and importance with collaborative digital literacy practices among adult learners in digital learning environments. Before and after participating in five different collaborative digital literacy practices (i.e., blogs, asynchronous discussions, wikis, microblog messages, and paired peer feedback), participants indicated their perceived levels of confidence and importance with each practice. It was hypothesized that no statistical significance was present with their reported perceptions. However, statistical significance was reported among all five collaborative digital literacy practices for perceived levels of confidence. Similarly, statistical significance was reported among all collaborative digital literacy practices for perceived levels of importance, with the exception of paired peer feedback. Closer examination of this finding with paired peer feedback showed that participants had rated their perceived levels of importance much higher before engagement with the practice than they did with the other collaborative digital literacy practices. After engagement with paired peer feedback, participants indicated an increase in their perceived levels of importance, albeit, the difference between these two means was not statically significant. It is important to note, though, descriptive statistics showed that participants had the most familiarity with this 
particular collaborative digital literacy practice. Therefore, they were likely already aware of its value in the learning process.

In the current study, collaborative digital literacy practices were implemented into the instructional design of a digital learning environment as a way to foster collaboration among adult learners through structured learning experiences. In addition to statistical significance, these findings have also suggested practical and theoretical significance within the context of adult education. Learning experiences that are learner-focused and address andragogical principles have been identified as effective instructional techniques for adult learners (Chang \& Chang, 2014; Ching \& Hsu, 2013; Hsu \& Ching, 2012; McDougall, 2015; Zheng et al., 2015). As learners interact with others, they make meaningful contributions individually (Dewey, 1938) while co-constructing knowledge (Vygotsky, 1978), which leads to mutual benefits for both the learner and the group (Gokhale, 1995). Digital learning environments are becoming increasingly ubiquitous; therefore, adult educators must use research-based efforts to identify effective instructional design methods that continue to provide quality learning experiences for learners (Fabry, 2009). Based on the findings reported in this study, adult learners viewed this approach with collaborative digital literacy practices as a valuable way to facilitate learning tasks within digital learning contexts.

\section{LIMITATIONS}

Although the current study presented findings for an area identified as one requiring additional research (Jacobs et al., 2014), there were limitations. First, the sample sizes for each statistical analysis met the requirements suggested by Cohen (1992) to detect a large difference between participants' pre- and post-test responses. However, it is recommended that replication studies should be conducted with larger sample sizes in order to confirm the findings, as well as detect smaller differences between the means. Another limitation was the current study explored only the perceptions of adult learners. Exploring perceptions among adult educators is of equal importance because a "technically 'literate' and innovative staff" (Greener \& Wakefield, 2015, p. 265) has been identified as a critical aspect for the effective integration of technology tools within digital learning environments. It is recommended that a follow-up study be conducted that explores perceived levels of confidence and importance with collaborative digital literacy practices among adult educators. Finally, the current study was exploratory and limited its analyses to perceived levels of confidence and importance. The impact that use of collaborative digital literacy practices has on academic performance was not explored. Therefore, it is recommended that future studies utilize an experimental design that explores the impact of collaborative digital literacy practices on adult learner academic performance.

\section{IMPLICATIONS}

Analyzing levels of confidence with technology tools among adult learners is of extreme importance, especially since technology has become a fundamental aspect of $21^{\text {st }}$ century learning (Lefever \& Current, 2010). Findings from the current study pointed to two central implications with perceived levels of confidence and importance for use of 
collaborative digital literacy practices among adult learners. First, the majority of participants had no previous experiences with three of the collaborative digital literacy practices (i.e., blogs, wikis, microblog messages). Although a little more than half of the participants indicated that they had previous experiences with the remaining two collaborative digital literacy practices (i.e., asynchronous discussions, paired peer feedback), findings demonstrated that these were new experiences for many of the participants. As indicated in the findings, participants rated their levels of confidence with each collaborative digital literacy practice higher after they participated in the related structured learning experience. Consequently, all analyses with levels of confidence produced statistically significant findings. Therefore, it is reasonable to conclude that increased use of collaborative digital literacy practices leads to increased levels of confidence among adult learners. Previous studies have suggested that increased levels of confidence lead to enhanced self-efficacy, which has a positive effect on learner behaviors (Chamberlain, Hillier, \& Signoretta, 2015; Mouton \& Roskam, 2015; Shoemaker, 2010).

The second implication from the current study has pointed to the significance of perceived levels of importance among adult learners with learning tasks. Utilizing a learner-centered approach to learning has been identified as an effective instructional design technique for adult learners (Knowles, 1984; Knowles, Holton III, \& Swanson, 2015), and supplanting learner-centered approaches into digital learning environments is vital for learner success (Blakely \& Sheffield, 2015; Conaway \& Zorn-Arnold, 2015, 2016a, 2016b). Much literature has demonstrated the need for adult educators to consider perceived levels of importance among their learners as they design curricula and related learning experiences (Almeida \& Vasconcelos, 2015; Fields, Hatala, \& Nauert, 2014). In doing so, adult educators enhance learner perceptions of relevance, as well as identify possible gaps that need to be addressed within the course.

\section{REFERENCES}

Almeida, A., \& Vasconcelos, C. (2015). Geoethics: Master's students' knowledge and perception of its importance. Research in Science Education, 45(6), 889-906. doi:10.1007/s11165-014-9449-3

Angelino, L. M., Williams, F. K., \& Natvig, D. (2007). Strategies to engage online students and reduce attrition rates. The Journal of Educators Online, 4(2), 1-14. Retrieved from https://www.thejeo.com/

Blackley, S., \& Sheffield, R. (2015). Digital andragogy: A richer blend of initial teacher education in the $21^{\text {st }}$ century. Issues in Educational Research, 25(4), 397-414. Retrieved from http://www.iier.org.au/iier25/blackley-2.html

Boling, E. C., Holan, E., Horbatt, B., Hough, M., Jean-Louis, J., Khurana, C., \& Spiezio, C. (2014). Using online tools for communication and collaboration: Understanding educators' experiences in an online course. The Internet and Higher Education, 23, 48-55. doi:10.1016/j.iheduc.2014.07.002

Chamberlain, J. M., Hillier, J., \& Signoretta, P. (2015). Counting better? An examination of the impact of quantitative method teaching on statistical anxiety and 
confidence. Active Learning in Higher Education, 16(1), 51-66. doi:10.1177/1469787414558983

Chang, Y., \& Chang, Y. (2014). Assessing peer support and usability of blogging in hybrid learning environments. Interactive Learning Environments, 22(1), 3-17. doi:10.1080/10494820.2011.619889

Ching, Y., \& Hsu, Y. (2016). Learners' interpersonal beliefs and generated feedback in an online role-playing peer-feedback activity: An exploratory study. International Review of Research in Open \& Distance Learning, 17(2), 105-122. Retrieved from http://www.irrodl.org/index.php/irrodl

Cohen, J. (1992). A power primer. Psychological Bulletin, 112(1), 155-159. doi:10.1037/0033-2909.112.1.155

Conaway, W., \& Zorn-Arnold, B. (2015). The keys to online learning for adults: The six principles of andragogy. Distance Learning, 12(4), 37-42. Retrieved from http://www.infoagepub.com/distance-learning

Conaway, W., \& Zorn-Arnold, B. (2016a). The keys to online learning for adults: The six principles of andragogy, Part II. Distance Learning, 13(1), 1-6. Retrieved from http://www.infoagepub.com/distance-learning

Conaway, W., \& Zorn-Arnold, B. (2016b). The keys to online learning for adults: The six principles of andragogy, Part III. Distance Learning, 13(2), 1-5. Retrieved from http://www.infoagepub.com/distance-learning

Creswell, J. W. (2013). Research design: Qualitative, quantitative, and mixed methods approaches $\left(4^{\text {th }}\right.$ ed.). Thousand Oaks, CA: SAGE Publications.

Dewey, J. (1938). Experience and education. New York, NY: Touchstone.

Eid, M. M., \& Al-Jabri, I. M. (2016). Social networking, knowledge sharing, and student learning: The case of university students. Computers \& Education, 99, 14-27. doi:10.1016/j.compedu.2016.04.007

Fabry, D. L. (2009). Designing online on on-ground courses to ensure comparability and consistency in meeting learning outcomes. The Quarterly Review of Distance Education, 10(3), 253-261. Retrieved from http://www.infoagepub.com/quarterlyreview-of-distance-education.html

Fields, T. T., Hatala, J. J., \& Nauert, R. F. (2014). Perceptions of preceptors and students on the importance of writing. Administrative Issues Journal: Education, Practice, and Research, 4(1), 1-11. doi:10.5929/2014.4.1.6

Gokhale, A. A. (1995). Collaborative learning enhances critical thinking. Journal of Technology Education, 7(1). doi:10.21061/jte.v7i1.a.2

Greener, S., \& Wakefield, C. (2015). Developing confidence in the use of digital tools in teaching. The Electronic Journal of e-Learning, 13(4), 260-267. Retrieved from http://www.ejel.org/main.html

Greenhow, C., \& Gleason, B. (2012) Twitteracy: Tweeting as a new literacy practice. The Educational Forum, 76(4), 464-478. doi:10.1080/00131725.2012.709032 
Hoskins, B. (2011). Demand, growth, and evolution. Journal of Continuing Higher Education, 59(1), 57-60. doi: 10.1080/07377363.2011.546267

Hsu, Y., \& Ching, Y. (2012). Mobile microblogging: Using Twitter and mobile devices in an online course to promote learning in authentic contexts. International Review of Research in Open and Distance Learning, 13(4), 211-227. Retrieved from http://www.irrodl.org/index.php/irrodl/index

Jacobs, G. E., Castek, J., Pizzolato, A., Reder, S., \& Pendell, K. (2014). Production and consumption: A closer look at adult digital literacy acquisition. Journal of Adolescent \& Adult Literacy, 57(8), 624-627. doi:10.1002/jaal.293

Journell, W. (2008). Facilitating historical discussions using asynchronous communication: The role of the teacher. Theory and Research in Social Education, 36(4), 317-355. doi:10.1080/00933104.2008.10473379

Kent, C., Laslo, E., \& Rafaeli, S. (2016). Interactivity in online discussions and learning outcomes. Computers \& Education, 97, 116-128. doi:10.1016/j.compedu.2016.03.002

Kissel, B., Hathaway, J. I., \& Wood, K. D. (2010). Digital collaborative literacy: Using wikis to promote social learning and literacy development. Middle School Journal, 41(5), 58-64. doi: 10.1080/00940771.2010.11461742

Knowles, M. S. (1984). Andragogy in action. Applying modern principles of adult education. San Francisco, CA: Jossey Bass.

Knowles, M. S., Holton III, E. F., \& Swanson, R. A. (2012). The adult learner: The definitive classic in adult education and human resource development $\left(7^{\text {th }} \mathrm{ed}.\right)$. Abington, UK: Routledge.

Ku, H., Tseng, H. W., \& Akarasriworn, C. (2013). Collaboration factors, teamwork satisfaction, and student attitudes towards online collaborative learning. Computers in Human Behavior, 29(3), 922-929. doi:10.1016/j.chb.2012.12.019

Laal, M., \& Ghodsi, S. M. (2011). Benefits of collaborative learning. Procedia - Social and Behavioral Sciences, 31, 486-490. Retrieved from http://www.journals.elsevier.com/procedia-social-and-behavioral-sciences/

Laerd Statistics. (2013). Dependent t-Test using SPSS Statistics. Retrieved from https://statistics.laerd.com/spss-tutorials/dependent-t-test-using-spss-statistics.php

Lefever, R., \& Currant, B. (2010). How can technology be used to improve learner experience at points of transition? Review of peer reviewed academic literature, national and international resources and examples of projects and initiatives within higher education institutions literature. Retrieved from http://technologyenhancedlearning.net/files/2010/04/ELESIGliteraturereviewFINAL240 210.pdf

Linder-VanBerschot, J. A., \& Summers, L. L. (2015). Designing instruction in the face of technology transience. Quarterly Review of Distance Education, 16(2), 107-118. Retrieved from http://www.infoagepub.com/quarterly-review-of-distance-education 
McDougall, J. (2015). The quest for authenticity: A study of an online discussion forum and the needs of adult learners. Australian Journal of Adult Learning, 55(1), 94-113. Retrieved from https://www.ajal.net.au/

Merriam, S. B. (2001). Andragogy and self-directed learning: Pillars of adult learning theory. New Directions for Adult and Continuing Education, 89, 3-14. doi:10.1002/ace.3

Mouton, B., \& Roskam, I. (2015). Confident mothers, easier ahildren: A quasiexperimental manipulation of mothers' self-efficacy. Journal of Child \& Family Studies, 24(8), 2485-2495. doi:10.1007/s10826-014-0051-0

Mudd, A., Summey, T., \& Upson, M. (2015). It takes a village to design a course: Embedding a librarian in course design. Journal of Library and Information Sciences in Distance Learning, 9(1-2), 69-88. doi:10.1080/1533290X.2014.946349

Ranker, J. (2015). The affordances of blogs and digital video: New potentials for exploring topics and representing meaning. Journal of Adolescent \& Adult Literacy, 58(7), 568-578. doi:10.1002/jaal.405

Scanlon, E., McAndrew, P., \& O’Shea, T. (2015). Designing for educational technology to enhance the experience of learners in distance education: How open educational resources, learning design and MOOCS are influencing learning. Journal of Interactive Media in Education, 6(1), 1-9. Retrieved from http://jime.open.ac.uk/

Sharp, L. A., \& Sharp, J. H. (2016). Enhancing student success in online learning experiences through the use of self-regulation strategies. Journal on Excellence in College Teaching, 27(2), 57-75. Retrieved from http://celt.miamioh.edu/ject/

Shoemaker, C. A. (2010). Student confidence as a measure of learning in an undergraduate principles of horticultural science course. Horttechnology, 20(4), 683688. Retrieved from http://horttech.ashspublications.org

Taylor, J. M., Dunn, M., \& Winn, S. K. (2015). Innovative orientation leads to improved success in online courses. Online Learning, 19(4), 112-120. Retrieved from https://olj.onlinelearningconsortium.org/index.php/olj/index

Tibbetts, J., \& Hector-Mason, A. (2015). Collaboration in adult education: Utilizing practices that reflect $21^{\text {st }}$ century learning contexts (Research Brief No. 12). Retrieved from http://www.calpro-online.org/pubs/CALPRO_Brief_No12_508.pdf

Vygotsky, L. S. (1978). Mind in society: The development of higher psychological processes. Cambridge, MA: Harvard University Press.

Zheng, B., Lawrence, J., Warschauer, M., \& Lin, C. (2015). Middle school students' writing and feedback in a cloud-based classroom environment. Technology, Knowledge and Learning, 20(2), 201-229. doi:10.1007/s10758-014-9239-z

Zheng, B., Niiya, M., \& Warschauer, M. (2015). Wikis and collaborative learning in higher education. Technology, Pedagogy \& Education, 24(3), 357-374. doi:10.1080/1475939X.2014.948041 